\title{
0077 THE SOLUTION OF WAIJO OR TEENAGER QUARRELLING AND FIGHTING PROBLEM
}

A Namprasert* Correspondence: Kaosuankwang police station, Kaosuankwang police station, Kaosuankwang district, Khon Kaen province 40000, Thailand

10.1136/ip.2010.029215.77

Background The word Waijo is a slang in Thai for teenager who tends to be a hooligan. They always act out violently and impetuous. They often attack other group by using illegal weapon or fighting especially in the community entertainment fair. Most of this case has been caused by drinking alcohol or having addictive substance. The statistic of this serious case tends to be increase every day.

Methodology This misbehaviour teenagers needs to be improved exactly. Bringing the group to be the community volunteer is the way to solve this problem. They first need to be adjusted their behaviour by using soldier method, then reminding them the danger of drug addict and teaching them about basic law in their daily life. And let them visit the hospital or the jail to share idea with the victim of violence or drug addict patients. These can build up the awareness of being legal people. Moreover, gathering them to be the volunteer network to prevent their own community is the main way to solve the problem. Most of them are accepted to be the youth leader to expand their new experience to the next group of violent teenagers. And this can be the strong network of young generation in community.

Result The hooligan role in community is reduced rapidly. Now, there are 198 volunteer teenagers who take action in community as the traffic policeman, school or community guard and so on. And there are also 212 volunteer club members in school.

Conclusion Now, Waijo teenagers who used to be harmful and has been looked down on by people around can turn to be new one by using behaviour adjustment process from the older. 